\title{
C. albicans growth, transition, biofilm formation, and gene expression modulation by antimicrobial decapeptide KSL-W
}

\author{
Simon Theberge ${ }^{1}$, Abdelhabib Semlali, ${ }^{1,2}$, Abdullah Alamri ${ }^{1}$, Kai P Leung ${ }^{3}$ and Mahmoud Rouabhia ${ }^{*}$
}

\begin{abstract}
Background: Antimicrobial peptides have been the focus of much research over the last decade because of their effectiveness and broad-spectrum activity against microbial pathogens. These peptides also participate in inflammation and the innate host defense system by modulating the immune function that promotes immune cell adhesion and migration as well as the respiratory burst, which makes them even more attractive as therapeutic agents. This has led to the synthesis of various antimicrobial peptides, including KSL-W (KKWFWWFK-NH 2 ), for potential clinical use. Because this peptide displays antimicrobial activity against bacteria, we sought to determine its antifungal effect on C. albicans. Growth, hyphal form, biofilm formation, and degradation were thus examined along with EFG1, NRG1, EAP1, HWP1, and SAP 2-4-5-6 gene expression by quantitative RT-PCR.

Results: This study demonstrates that KSL-W markedly reduced C. albicans growth at both early and late incubation times. The significant effect of KSL-W on C. albicans growth was observed beginning at $10 \mu \mathrm{g} / \mathrm{ml}$ after $5 \mathrm{~h}$ of contact by reducing C. albicans transition and at $25 \mu \mathrm{g} / \mathrm{ml}$ by completely inhibiting C. albicans transition. Cultured C. albicans under biofilm-inducing conditions revealed that both KSL-W and amphotericin B significantly decreased biofilm formation at 2, 4 , and 6 days of culture. KSL-W also disrupted mature C. albicans biofilms. The effect of KSL-W on C. albicans growth, transition, and biofilm formation/disruption may thus occur through gene modulation, as the expression of various genes involved in C. albicans growth, transition and biofilm formation were all downregulated when C. albicans was treated with KSL-W. The effect was greater when C. albicans was cultured under hyphae-inducing conditions.
\end{abstract}

Conclusions: These data provide new insight into the efficacy of KSL-W against C. albicans and its potential use as an antifungal therapy.

Keywords: Antimicrobial peptide, KSL-W, C. albicans, Growth, Hyphae, Gene, EFG1, NRG1, HWP1, SAPs

\section{Background}

The innate defense system plays a key role in protecting the host against microorganism-fueled infections such as candidiasis caused by Candida albicans. C. albicans colonizes several body sites, including the oral cavity; however, as a commensal organism, it causes no apparent damage or inflammation in the surrounding tissue $[1,2]$. C. albicans is a polymorphic organism that adheres to different surfaces in the body and can grow as yeast, pseudohyphae, and hyphae [3], usually in the form of biofilm. C. albicans transition, biofilm formation, and

\footnotetext{
* Correspondence: mahmoud.rouabhia@fmd.ulaval.ca

${ }^{1}$ Oral Ecology Research Group, Faculty of Dentistry, Laval University, 2420,

rue de la Terrasse, Quebec G1V 0A6, QC, Canada

Full list of author information is available at the end of the article
}

pathogenesis are under the control of various genes. The HWP1 gene encodes the hyphal cell wall protein, which is a hyphal-specific adhesin that is essential to biofilm formation [4]. The involvement of HWP1 in C. albicans adhesion is supported by the EAP1 gene which encodes a glucan-crosslinked cell wall protein (adhesin Eap1p). Together, these components mediate C. albicans adhesion to various surfaces, such as epithelial cells and polystyrene [5]. Like many other genes, HWP1 and EAP1 are downstream effectors of EFG1 and NRG1 as transcription factors [6,7]. EFG1 mutant strain has been shown to exhibit defects in growth, biofilm formation, and virulence [8], while NRG1 represses filamentous growth [3]. This occurs through the DNA binding protein Nrg1p in conjunction with the global transcriptional repressor

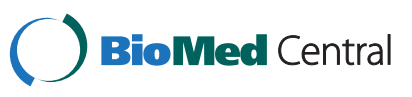


Tup1p to suppress hyphal formation. Elevated NRG1 expression represses the expression of a number of hypha-specific genes, although NRG1 downregulation is associated with $C$. albicans filaments [3].

C. albicans virulence is also mediated by proteolytic enzymes, including secreted aspartyl proteinases (SAPs) $[9,10]$. The contribution of SAPs in C. albicans adherence, tissue damage, and evasion of host immune responses has been reported [9]. SAP2 is crucial to $C$. albicans growth in protein-containing media [11]. SAP1 and SAP3 are expressed during phenotypic switching $[12,13]$, while SAP4, SAP5, and SAP6 are expressed upon hyphal formation [14], and SAPs 1-6 and 9-10 are involved in the adhesion mechanism to host cells [15].

To control C. albicans pathogenesis, the host innate immunity uses small molecules such as proteins and peptides that display a broad antimicrobial spectrum. The number of identified potentially antimicrobial peptides is significant and continues to increase [16]. Antimicrobial peptides often possess common attributes, such as small size, an overall positive charge, and amphipathicity $[17,18]$; however, they also fall into a number of distinctively diverse groups, including $\alpha$-helical peptides, $\beta$-sheet peptides, peptides with mixed $\alpha$-helical and $\beta$-sheet structures, extended peptides, and peptides enriched in specific amino acids [16].

In humans, epithelial cells and neutrophils are the most important cells producing antimicrobial peptides $[19,20]$. These peptides are most often antibacterial, although antifungal activity has also been reported [16,21]. The major peptide groups known to date are the histatins, cathelicidins, defensins, and lactoferricins [22]. The antimicrobial activity of these peptides has been reported by different in vitro and in vivo studies $[19,20,22]$. Their complex role as well as their contribution to host defenses may be related to the functional interrelationship between innate and adaptive immunity [23,24].

The interest in antimicrobial peptides lies in the possible resistance of microorganisms to conventional antimicrobial strategies used against microbial pathogens in both agriculture and medicine [25,26]. Natural antimicrobial peptides are necessary in the control of microbial infections. For example, the use of AMPs provided protection against such microbial pathogens as fungal pathogens, with no reported effect on the host $[27,28]$. Based on these promising data, a number of synthetic AMPs have been designed to overcome microbial infections [29]. In the pursuit of a novel alternative antifungal treatment, we developed a synthetic $\alpha$-helical antimicrobial decapeptide, KSL (KKVVFKVKFK), and its analogue KSL-W (KKVVFWVKFK) [30].

The efficacy of KSL on a wide range of microorganisms has been established [31-33], as well as its ability to disrupt oral biofilm growth [34]. KSL-W, a recently synthesized KSL analogue, was shown to display improved stability in simulated oral and gastric conditions with in vitro preserved antimicrobial activity [30]. Furthermore, combined with sub-inhibitory concentrations of benzalkonium chloride, a known cationic surfaceactive agent [35], KSL was shown to significantly promote bacterial biofilm susceptibility. We also recently demonstrated that KSL-W had a selective effect on $C$. albicans growth, while exhibiting no toxic effect on epithelial cells [36].

As this KSL-W analogue displays a wide range of microbicidal activities, effectively kills bacteria, controls biofilm formation, and destroys intact biofilms, we hypothesized that KSL-W may also possess antifungal potential. Our goal was thus to investigate the ability of KSL-W to inhibit $C$. albicans growth and transition from blastospore to hyphal form. The action of KSL-W on biofilm formation/disruption was also assessed. Finally, we examined the effect of KSL-W on various $C$. albicans genes involved in its growth, transition, and virulence.

\section{Results}

\section{Antimicrobial peptide KSL-W reduced C. albicans growth} and transition from blastospore to hyphal form

C. albicans cultures were incubated with KSL-W for 5, 10 , and $15 \mathrm{~h}$ to determine whether this antimicrobial peptide had any adverse effect on C. albicans growth. As shown in Figure 1, KSL-W significantly reduced C. albicans proliferation. After $5 \mathrm{~h}$ of contact with KSL-W, the growth inhibition of $C$. albicans was between 30 and $80 \%$, depending on the concentration of KSL-W used (Figure 1A). After $10 \mathrm{~h}$ of contact with KSL-W, growth inhibition was significant, beginning at $25 \mu \mathrm{g} / \mathrm{ml}$ (Figure 1B). At later culture periods, C. albicans growth continued to be significantly affected by the presence of KSL-W (Figure 1C). Indeed, with $25 \mu \mathrm{g} / \mathrm{ml}$ of KSL-W, C. albicans growth was almost half that in the controls (non-treated C. albicans cultures), and with $100 \mu \mathrm{g} / \mathrm{ml}$ of KSL-W, C. albicans growth was reduced by almost $60 \%$. It is interesting to note that KSL-W in as low as $25 \mu \mathrm{g} / \mathrm{ml}$ was effective at both the early and late culture periods.

As KSL-W contributed to C. albicans growth inhibition, we hypothesized that it would also downregulate C. albicans transition from yeast form to hyphal phenotype. Yeast cultures supplemented with 10\% FBS and the KSL-W peptide were maintained for various incubation periods. As shown in Figure 2, germ tube formation was inhibited as early as $4 \mathrm{~h}$ following exposure to the peptide, compared to that in the cultures incubated in the absence of KSL-W. Of interest is the elevated number of C. albicans hyphal forms in the negative control culture (no KSL-W or amphotericin B) compared to the low number in the presence of KSL-W. The effect of this 


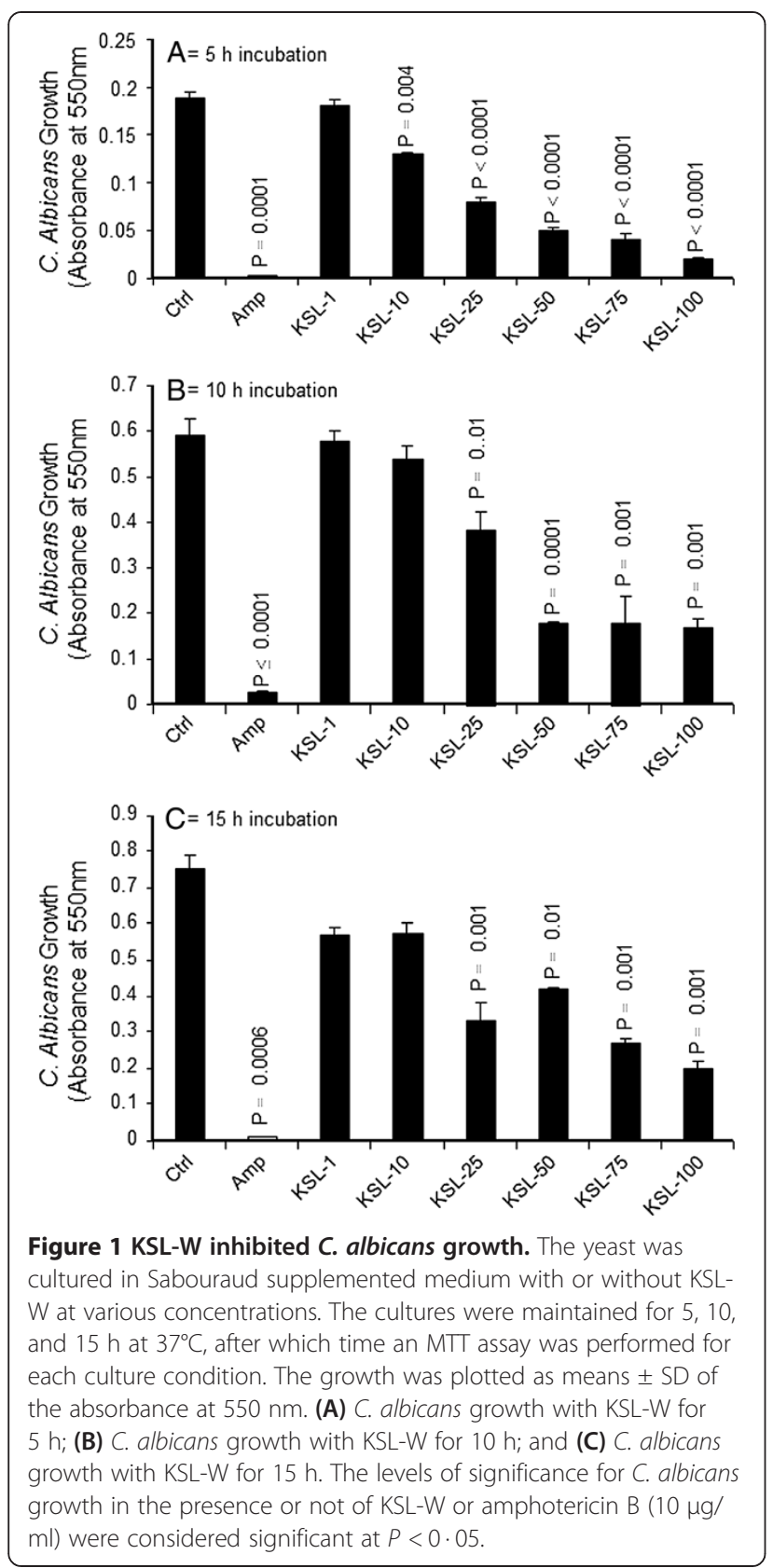

antimicrobial peptide on C. albicans transition was also dose-dependent: at $1 \mu \mathrm{g} / \mathrm{ml}$, a significant number of hyphal forms remained, and at only $5 \mu \mathrm{g} / \mathrm{ml}$ of KSL-W, $C$. albicans transition was completely inhibited (Figure 2). Semi-quantitative analyses using inverted microscope observations to estimate the hyphal forms confirmed the inhibited C. albicans transition when treated with KSL-W (Table 1). The density of the hyphae was reduced as early as $4 \mathrm{~h}$ of contact with $5 \mu \mathrm{g} / \mathrm{ml}$ of KSL-W. This effect was further supported when C. albicans was placed in contact with KSL-W for $8 \mathrm{~h}$ (Table 1), thus confirming that KSL-W downregulated $C$. albicans growth and transition.

\section{KSL-W reduced C. albicans biofilm formation}

As KSL-W contributed to reducing $C$. albicans growth and transition, we sought to determine whether it also displayed inhibitory activity against $C$. albicans biofilm formation. Using a biofilm-promoting scaffold, SEM analyses, and an XTT assay, we were able to demonstrate the inhibitory effect of KSL-W on biofilm formation (Figure 3). SEM analyses revealed a significant density of C. albicans in the untreated culture, compared to a lower density in the scaffold in the presence of KSL-W (1 and $25 \mu \mathrm{g} / \mathrm{ml}$ ) after 4 days of culture. The decreases obtained with the KSL-W, particularly at $25 \mu \mathrm{g} / \mathrm{ml}$ (Figure 3), were comparable to that obtained with amphotericin B at $10 \mu \mathrm{g} / \mathrm{ml}$. To confirm these observations, we performed quantitative analyses using the XTT assay. Figure 4A shows that after 2 days of culture, KSL-W was able to inhibit biofilm formation. This inhibitory effect was observed beginning at $25 \mu \mathrm{g} / \mathrm{ml}$ of KSL-W. At concentrations of 50,75 , and $100 \mu \mathrm{g} / \mathrm{ml}$ of $\mathrm{KSL}-\mathrm{W}$, the inhibition of $C$. albicans biofilm formation was comparable to that caused by amphotericin B at $10 \mu \mathrm{g} / \mathrm{ml}$. Similar results were obtained after 4 days (Figure 4B) and 6 days (Figure $4 \mathrm{C}$ ) of culture for biofilm formation with a persistent inhibitory effect of KSL-W on C. albicans biofilm formation.

\section{KSL-W disrupted mature C. albicans biofilms}

After 6 days of incubation in glucose-rich Sabouraud medium, scaffolds seeded with C. albicans strain SC5314 produced mature biofilms displaying highly dense populations of Candida cells (Figure 5). Significant reductions and disruptions of the pre-formed Candida biofilms were observed when the reference antifungal agent (amphotericin B, $10 \mu \mathrm{g} / \mathrm{ml}$ ) was added to the mature biofilms upon further incubation up to 6 days. Similarly, antimicrobial peptide KSL-W at 75 and $100 \mu \mathrm{g} / \mathrm{ml}$ also reduced $C$. albicans density in the biofilms. The observed reduction was noticed with KSL-W concentrations ranging from 25 to $100 \mu \mathrm{g} / \mathrm{ml}$. Indeed, when quantitatively investigated by XTT reduction assay, the KSL-W-treated biofilms rendered a significantly lower number of cells, as reflected by the lower absorbance readings, than did the untreated control. This effect was observed after 2, 4, and 6 days of treatment with amphotericin B. Furthermore, the effect of KSL-W on the mature C. albicans biofilm was comparable to that obtained with amphotericin B (Figure 6).

\section{KSL-W modulated the expression of various C. albicans genes}

Based on the data showing that KSL-W reduced C. albicans proliferation, transition, and biofilm formation, we sought to determine the involvement, if any, of gene regulation. For this purpose, we first investigated the 


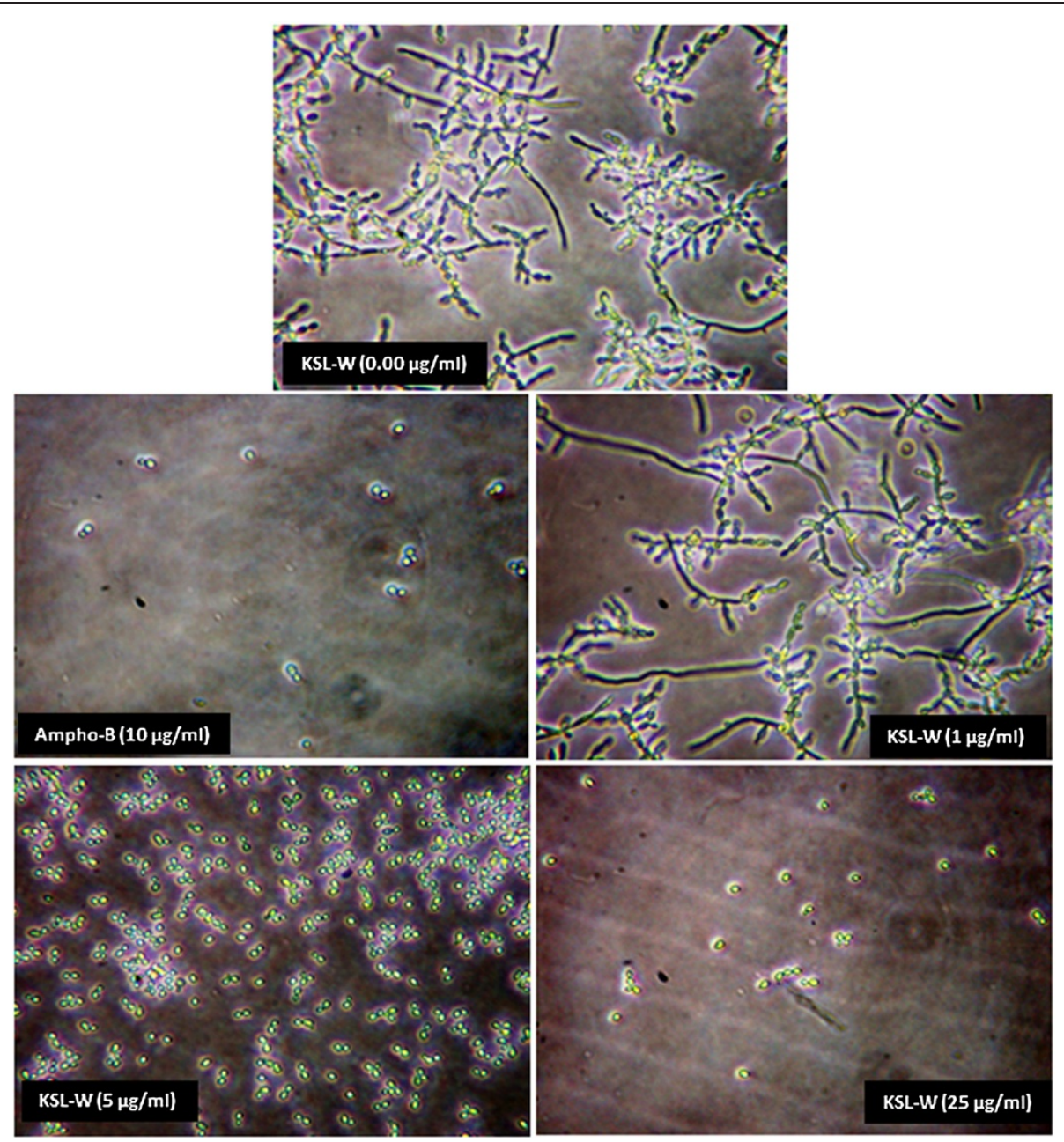

Figure 2 KSL-W inhibited C. albicans yeast-to-hyphae transition. C. albicans was cultured in Sabouraud medium containing 10\% fetal bovine serum with or without KSL-W at various concentrations and was maintained for 4 and $8 \mathrm{~h}$ at $37^{\circ} \mathrm{C}$. After each time point, the cultures were observed under an inverted microscope and photographed. Representative photos of the morphological changes after $4 \mathrm{~h}$ of culture are presented.

Table 1 Estimation of hyphae forms in the C. albicans culture

\begin{tabular}{lccc}
\hline Active molecules & $\begin{array}{c}\text { Concentration } \\
(\boldsymbol{\mu g} / \mathbf{m L})\end{array}$ & $\begin{array}{c}\text { Transition } \\
\text { at } \mathbf{4} \mathbf{~ h}\end{array}$ & $\begin{array}{c}\text { Transition } \\
\text { at } \mathbf{8 ~ h ~}\end{array}$ \\
\hline Negative control & 0 & ++ & ++ \\
KSL-W & 1 & ++ & ++ \\
5 & 10 & - & - \\
& 15 & - & - \\
25 & - & - \\
Amphotericin B & 100 & - & - \\
\hline
\end{tabular}

This Table depicts the presence of hyphae following 4 and $8 \mathrm{~h}$ treatments of $C$. albicans with and without KSL-W or amphotericin B. (-) refers to the absence hyphae form, and $(++)$ refers to the presence high number of hyphae forms. These data were estimated after evaluation over 20 fields from each culture condition, by two independent and blinded examiners. effect of KSL-W on the activation/repression of various C. albicans genes when cultured under normal nonhyphae-inducing conditions. The data in Table 2 indicate that the HWP1 gene was significantly downregulated following exposure of the C. albicans to KSL-W for $6 \mathrm{~h}$. This downregulation was comparable to that observed in the amphotericin B treatment. Similarly, SAPs 2, 4, 5, and 6 were significantly downregulated by KSL-W treatment after $6 \mathrm{~h}$ (Table 2). This effect was observed with both low and high concentrations of KSL-W. Furthermore, the EAP1 gene, which encodes a glycosylphosphatidylinositolanchored, glucan-crosslinked cell wall protein in both adhesion and biofilm formation in vitro and in vivo, was also affected by the KSL-W treatment. Moreover, the expression of this gene was downregulated by KSL-W, yet was upregulated (up to 5 -fold) by amphotericin B.

Two other genes involved in regulating $C$. albicans morphogenesis, namely, EFG1 and NRG1, are known to 


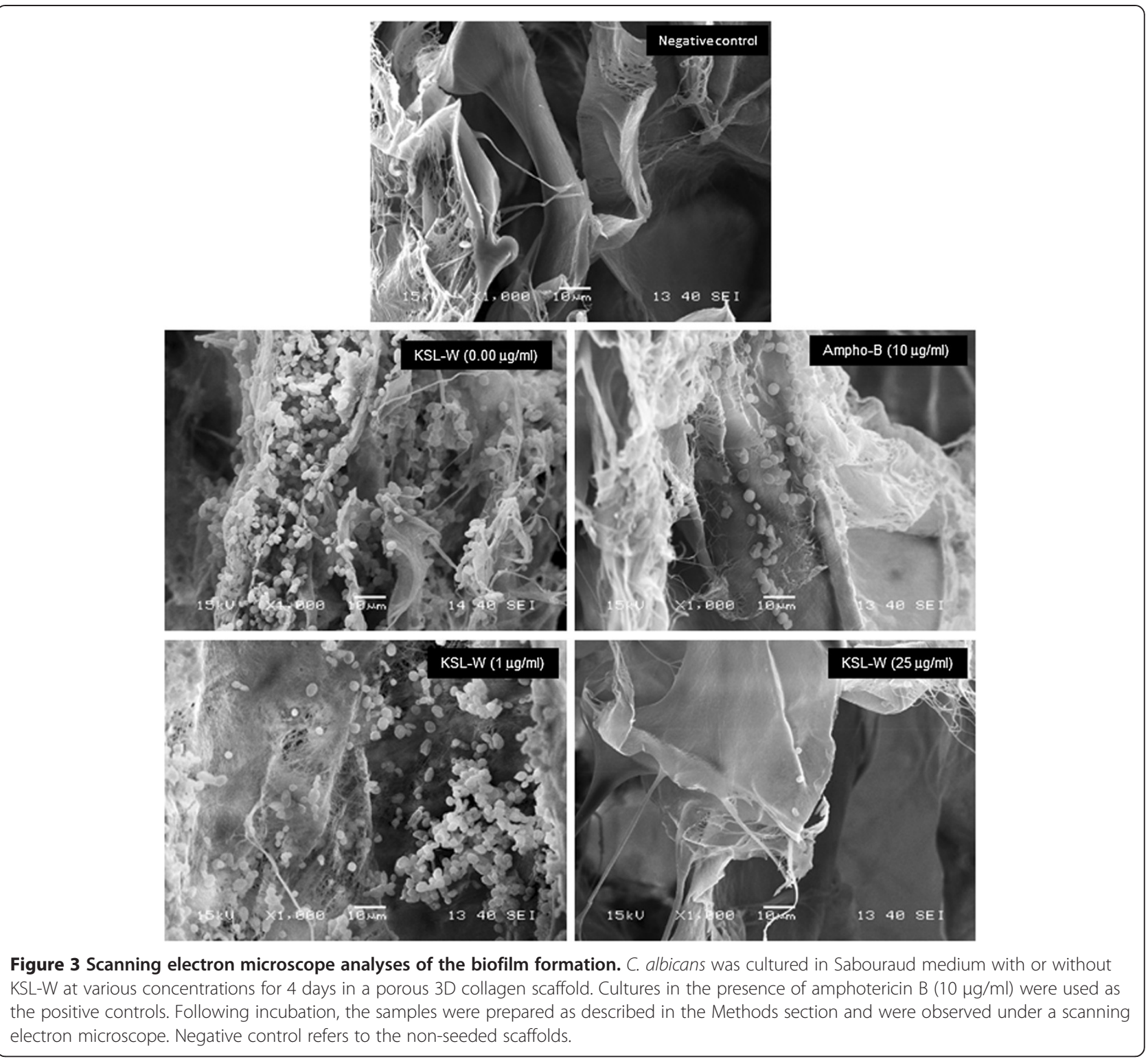

be hyphae repressors. In our study, amphotericin B increased both EFG1 and NRG1 mRNA expression, with twice as much expression for NRG1 than for EFG1 (Table 3), while KSL-W induced a less significant increase of EFG1 and NRG1 mRNA expression. Of interest is that a low KSL-W concentration $(25 \mu \mathrm{g} / \mathrm{ml})$ induced greater gene expression (Table 3).

In a second set of experiments, C. albicans was cultured under hyphae-inducing conditions (fetal calf serum-enriched medium with incubation at $37^{\circ} \mathrm{C}$ ) in the presence or not of KSL-W, after which time gene expression/repression was investigated. The data in Table 4 reveal that similar to the results obtained with amphotericin-B, the HWP1 gene was significantly ( $\mathrm{p}<$ 0.0001) downregulated when $C$. albicans was exposed to
KSL-W for $3 \mathrm{~h}$, confirming the results obtained under non-hyphae growth conditions.

SAP genes were also modulated by KSL-W treatment. Table 4 shows that after $3 \mathrm{~h}$ of exposure, SAPs 2, 4, 5, and 6 were significantly $(\mathrm{p}<0.05)$ downregulated by the KSL-W treatment. In contrast, with amphotericin-B, a significant $(\mathrm{p}<0.05)$ increase of SAPS 2, 4, and 6 and a decrease of SAP5 was observed. It is interesting to note the opposite modulatory effects of KSL-W and amphotericinB on SAP gene expression. After $6 \mathrm{~h}$ of treatment with KSL-W, a significant decrease of each tested SAP gene was observed in the exposed $C$. albicans, whereas after treatment with amphotericin-B, these same SAP genes increased, thus confirming the antagonistic behavior of KSL-W and amphotericin-B on SAP gene expression. 


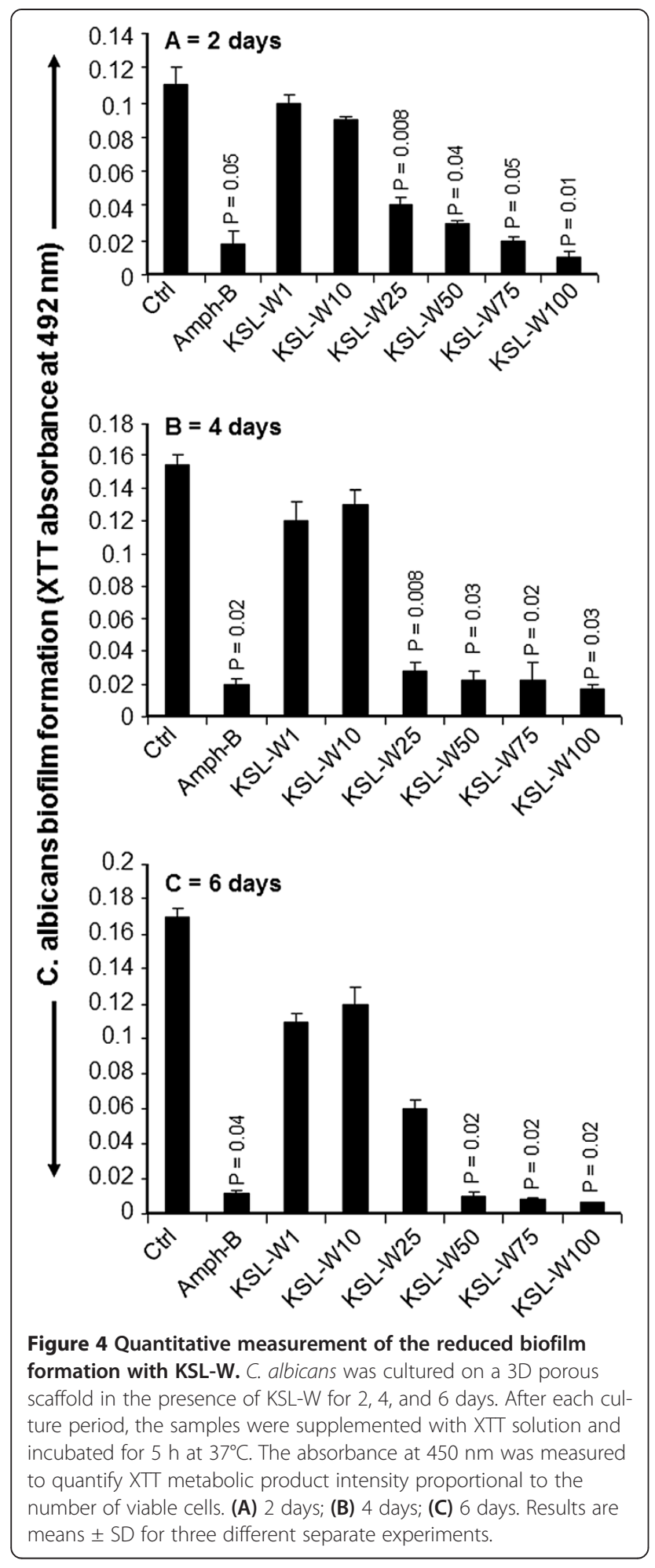

C. albicans EAP1 gene expression was unchanged after $3 \mathrm{~h}$ with KSL-W, but significantly $(\mathrm{p}<0.001)$ decreased after $6 \mathrm{~h}$, while the expression of this gene was upregulated (close to six folds) by amphotericin B (Tables 4 and 5). Amphotericin B increased NRG1 mRNA expression almost threefold, with no significant effect on the EFG1 gene, yet significantly decreased HWP1 gene expression. On the other hand, after $3 \mathrm{~h}$ (Table 4) and $6 \mathrm{~h}$ (Table 5) of incubation, KSL-W downregulated EFG1, NRG1, and HWP1 mRNA expression. Of interest is that except for similar downregulatory effects on HWP1 gene expression, KSL-W and amphotericin-B produced once again opposite results regarding EFG1and NRG1 gene expression.

\section{Discussion and conclusions}

We demonstrated that KSL-W was effective in inhibiting C. albicans growth at short and long culture periods. Although growth inhibition obtained with KSL-W was less than that obtained with amphotericin $\mathrm{B}$, the effects of KSL-W nevertheless remain significant $(p<0.01)$. The growth inhibition effects of KSL-W are in accordance with previously reported findings [37] showing a downregulation of C. albicans activity induced by a bacteriocin-like peptide isolated from Lactobacillus pentosus. Furthermore, our results support other findings [38] reporting the effectiveness of KSL-W in disrupting $P$. gingivalis-induced hemagglutination and its synergistic interaction with host AMPs engaged in innate defense. The results strongly suggest that KSL-W is also effective against fungal growth and may be suitable for use to control C. albicans infections. Further studies on the possible synergistic effect of amphotericin B and KSL-W against C. albicans growth may provide insight.

C. albicans pathogenesis can also take place through the transition from blastospore to hyphal form $[39,40]$. Our results indeed show that KSL-W completely inhibited $C$. albicans transition with a concentration as low as $5 \mu \mathrm{g} / \mathrm{ml}$. These data are consistent with those of other studies with naturally occurring antimicrobial peptides (e.g., $\beta$-defensins) which were effective in blocking the morphological shift of Candida from yeast to hyphae $[41,42]$. Thus KSL-W may possibly contribute to the control of C. albicans infection by reducing cell growth and yeast-hyphae transition. The effect of KSL-W on $C$. albicans growth can occur either through cytolysis or cell membrane disruption, resulting in cell death similar to what has been demonstrated with histatin-5 $[43,44]$. Indeed, it was shown that histatin-5 induces the selective leakage of intracellular ions and ATP from yeast cells. This is caused by the translocation of histatin- 5 into the intracellular compartment and accumulates to a critical concentration [45]. Further studies are thus warranted to shed light on the fungicidal mechanism of KSL-W.

C. albicans growth and transition from blastospore to hyphal form are particularly important for biofilm formation and $C$. albicans virulence because a strain that is genetically manipulated to grow exclusively in the yeast form is greatly hindered in generating biofilms. In addition, a variety of $C$. albicans mutants known to be 

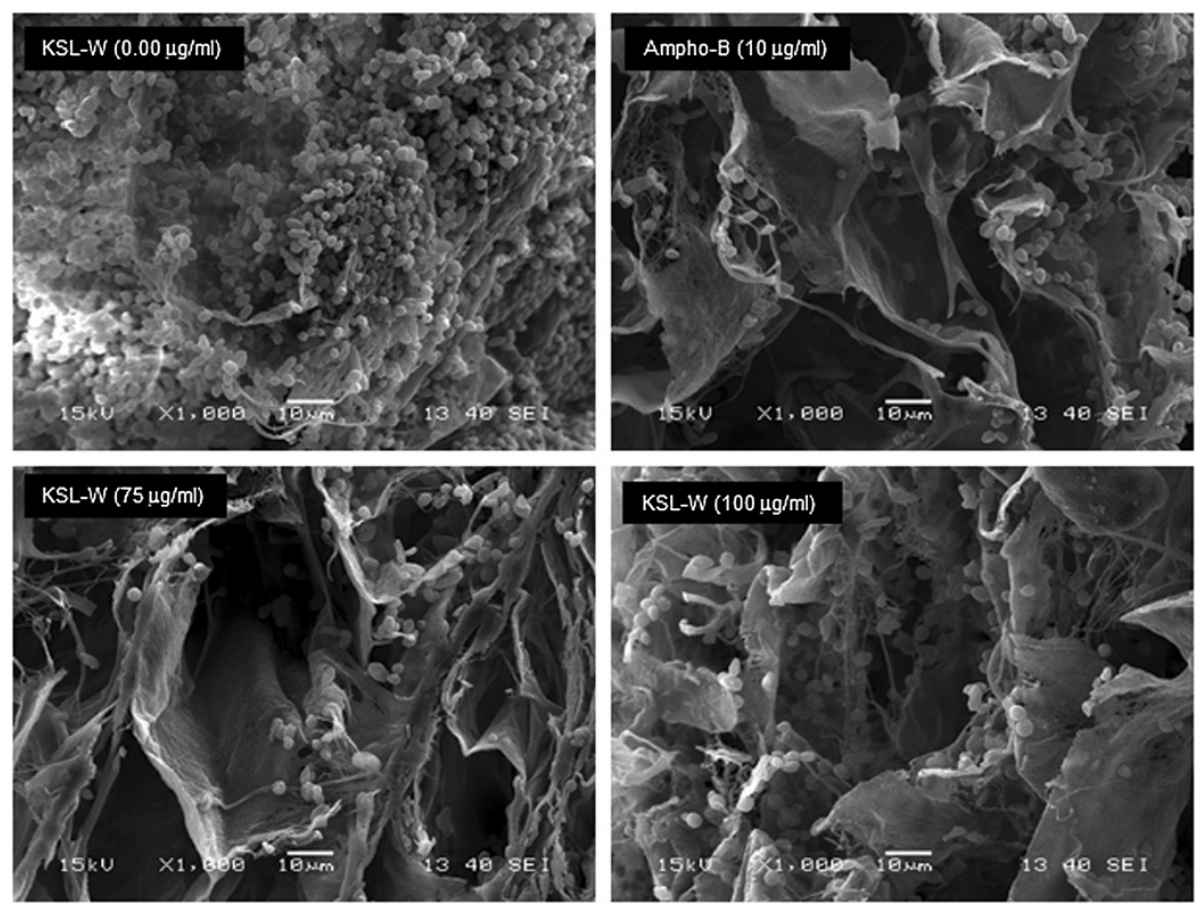

Figure 5 Biofilm ultrastructure following KSL-W treatment. C. albicans was cultured in Sabouraud medium without KSL-W for 6 days to promote biofilm formation and maturation. The resulting biofilms were then treated or not with KSL-W or amphotericin B for 6 days, with medium and peptide refreshing every 2 days. Following incubation, the samples were prepared as described in the Methods section and observed under a scanning electron microscope.

unable to form hyphae also show biofilm defects [46,47]. As KSL-W significantly reduced $C$. albicans growth and inhibited its transition from yeast to hyphae, this suggests that KSL-W may inhibit $C$. albicans biofilm formation. Our findings indicate that KSL-W was indeed able to reduce biofilm formation and that its effect was comparable to that obtained with amphotericin $\mathrm{B}$, a wellknown antifungal molecule. Also of interest is that a significant inhibition of $C$. albicans biofilm formation was obtained at a concentration of as low as $25 \mu \mathrm{g} / \mathrm{ml}$ of KSL-W antimicrobial peptide. These useful data are comparable to those of other studies showing the positive action of synthetic peptide in controlling and preventing microbial biofilm formation [48]. Thus, with its significant impact in reducing C. albicans biofilm formation, KSL-W may show potential for several novel applications in the clinical setting. Further investigations will elucidate this effect.

Biofilm formation can be controlled with anti-biofilm molecules prior to its development, although this is not actually the case in clinical applications, as antifungal and microbial molecules cannot be used on a daily basis to prevent biofilm formation. An effective molecule should ideally be able to prevent biofilm formation, but more importantly to disrupt biofilms that are already formed. We therefore questioned whether KSL-W was capable of disrupting mature C. albicans biofilm.
We proceeded to examine the impact of KSL-W on mature biofilm formation and demonstrated a significant disruption of these biofilms following contact with KSL-W, thus suggesting the possible use of this antimicrobial peptide to reduce/eliminate mature biofilms. Further studies should confirm such observations and demonstrate how KSL-W reduces or disrupts $C$. albicans biofilms.

Once it reaches the cell, KSL-W can potentially act on the cytoplasmic membrane as well as on intracellular targets [49-51]. The action of KSL-W against C. albicans may operate through the modulated expression of certain C. albicans genes that control growth [52], transition [53], and biofilm formation [54]. We therefore examined the effect of KSL-W on a number of genes either directly or indirectly involved in phase transition and biofilm formation. EFG1 and NRG1 expression was assessed under hyphae/non-hyphae-inducing conditions. Our results show that KSL-W increased NRG1 mRNA expression twofold under non-hyphae-inducing conditions; however, under hyphae-inducing conditions, KSLW significantly reduced NRG1 gene expression. These findings contrast with other reports that an increased NRG1 expression contributes to repressing various hypha-specific genes $[55,56]$. This confirms that the effect of KSL-W in controlling C. albicans virulence does not take place through NRG1. KSL-W was also able to 


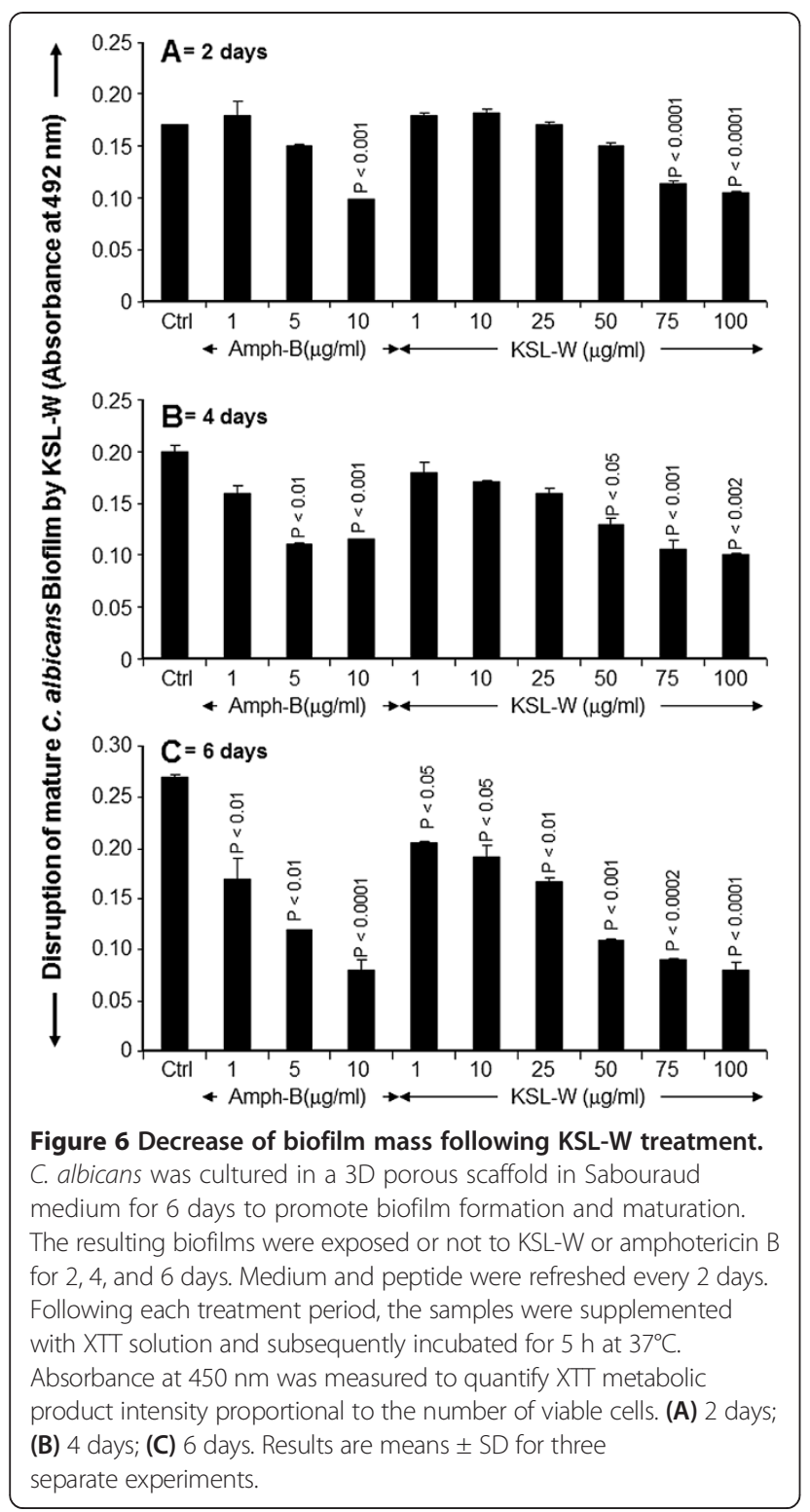

decrease EFG1 mRNA expression, when $C$. albicans was maintained under hyphae-inducing conditions.

EFG1p has been found to be a central regulator of C. albicans, as it is required for the development of a true hyphal growth form, and EFG1 is considered to be essential in the interactions between $C$. albicans and human host cells $[7,8]$. The downregulation of this gene by KSL-W points to the singular role of this antifungal peptide. Thus the effect of KSL-W on C. albicans transition can be manifested through a repression of certain genes, such as EFG1 and NRG1.

KSL-W has a significant inhibitory effect on EAP1 mRNA expression. As a member of the GPI-CWP family [5,57], deleting EAP1 can reduce the adhesion of $C$. albicans to different surfaces. This suggests that treatment with KSL-W may reduce EAP1 expression, which in turn may contribute to reducing $C$. albicans adhesion and ultimately, biofilm formation and pathogenesis. KSL-W was also shown to reduce HWP1 mRNA expression, particularly when C. albicans was cultured under hyphae-inducing conditions.

HWP1 is a downstream component of the cAMPdependent PKA pathway and is positively regulated by EFG1 [58]. The transcript level of HWP1 decreased with the KSL-W treatment at low and high concentrations. These data suggest that KSL-W indeed impacts the activity of the cAMP-EFG1 pathway and leads to an alteration of $C$. albicans growth and morphogenesis. Further studies are therefore required to investigate the invasion/virulence of KSL-W-treated C. albicans.

It is well known that Candida pathogenesis can be established by virtue of Candida growth and yeast-tohyphae morphogenesis. Specific SAP genes were found to be preferentially expressed by Candida hyphal forms $[10,15,59]$. Because KSL-W downregulated C. albicans growth and transition, this may have occurred through a modulation of the SAP genes. Our findings confirm that KSL-W is capable of decreasing SAP2, SAP4, SAP5, and SAP6 mRNA expression in C. albicans which may lead to reducing C. albicans virulence [60-62].

Our study thus establishes, for the first time, a clear link between an antimicrobial peptide (KSL-W), hyphae

Table 2 Gene expression (6 h) under non-hyphae inducing culture conditions

\begin{tabular}{|c|c|c|c|c|c|c|c|}
\hline \multirow[t]{2}{*}{ Gene } & \multirow{2}{*}{$\begin{array}{l}\text { Untreated C. albicans } \\
\text { Fold change }^{1}\end{array}$} & \multicolumn{2}{|c|}{ Amphotericin B } & \multicolumn{2}{|c|}{ KSL-W $25 \mu \mathrm{g} / \mathrm{ml}$} & \multicolumn{2}{|c|}{ KSL-W $100 \mu \mathrm{g} / \mathrm{ml}$} \\
\hline & & Fold change $^{1}$ & $p$-value ${ }^{2}$ & Fold change $^{1}$ & $p$-value ${ }^{2}$ & Fold change $^{1}$ & p-value ${ }^{2}$ \\
\hline SAP2 & 0.99 & 0.57 & 0.001 & 0.24 & $<0.001$ & 0.11 & $<0.001$ \\
\hline SAP4 & 0.96 & 0.19 & $<0.001$ & 0.29 & $<0.001$ & 0.14 & $<0.001$ \\
\hline SAP5 & 1.00 & 0.08 & $<0.001$ & 0.16 & $<0.001$ & 0.06 & $<0.001$ \\
\hline SAP6 & 1.00 & 0.05 & $<0.001$ & 0.14 & $<0.001$ & 0.04 & $<0.001$ \\
\hline EAP1 & 1.00 & 4.91 & 0.028 & 0.4 & $<0.001$ & 0.29 & $<0.001$ \\
\hline HWP1 & 1.00 & 0.01 & $<0.001$ & 0.6 & 0.032 & 0.02 & $<0.001$ \\
\hline
\end{tabular}

${ }^{1}$ Fold change was calculated by PCR product of the gene of interest/the PCR product of ACT1 (the house keeping gene), and normalized to the negative control of untreated C. albicans where the expression was considered equal to 1.

${ }^{2} \mathrm{P}$-values were obtained after comparison of test to negative control (untreated C. albicans). 
Table 3 Gene expression ( $3 \mathbf{h}$ ) under non-hyphae inducing culture conditions

\begin{tabular}{|c|c|c|c|c|c|c|c|}
\hline \multirow[t]{2}{*}{ Gene } & \multirow{2}{*}{$\begin{array}{l}\text { Untreated C. albicans } \\
\text { Fold change }^{1}\end{array}$} & \multicolumn{2}{|c|}{ Amphotericin B } & \multicolumn{2}{|c|}{ KSL-W $25 \mu \mathrm{g} / \mathrm{ml}$} & \multicolumn{2}{|c|}{ KSL-W $100 \mu \mathrm{g} / \mathrm{ml}$} \\
\hline & & Fold change $^{1}$ & p-value ${ }^{2}$ & Fold change $^{1}$ & p-value ${ }^{2}$ & Fold change $^{1}$ & $p$-value ${ }^{2}$ \\
\hline EFG1 & 1.00 & 5.71 & $<0.001$ & 2.76 & $<0.001$ & 1.98 & 0.073 \\
\hline$N R G 1$ & 1.00 & 10.99 & $<0.001$ & 1.77 & $<0.001$ & 1.4 & 0.086 \\
\hline
\end{tabular}

${ }^{1}$ Fold change was calculated by PCR product of the gene of interest/the PCR product of ACT1 (the house keeping gene), and normalized to the negative control of untreated C. albicans where the expression was considered equal to 1.

${ }^{2} \mathrm{P}$-values were obtained after comparison of test to negative control (untreated C. albicans).

morphogenesis, and hyphae-modulating SAPs 2, 4, 5, and 6. However, the precise interactions between these SAPs and KSL-W during C. albicans pathogenesis remain unclear. Additional studies should focus on identifying the role of SAP subfamilies involved in Candida invasion as well as the role of KSL-W in controlling Candida virulence/pathogenesis in conjunction with host defenses. In conclusion, this study is the first to demonstrate that synthetic antimicrobial peptide KSL-W downregulates $C$. albicans growth and transition, resulting in a decrease in biofilm formation and a disruption of mature biofilm. Also of interest is that these effects may occur through the modulation of $C$. albicans genes EFG1, NRG1, EAP1, HWP1, and SAPs. Overall results clearly suggest the potential of KSL-W as an antifungal molecule.

\section{Methods}

\section{C. albicans}

C. albicans strain ATCC-SC5314 was cultured for $24 \mathrm{~h}$ on Sabouraud dextrose agar plates (Becton Dickinson, Oakville, $\mathrm{ON}$, Canada) at $30^{\circ} \mathrm{C}$. For the C. albicans suspensions, one colony was used to inoculate $10 \mathrm{ml}$ of Sabouraud liquid medium supplemented with $0.1 \%$ glucose at $\mathrm{pH}$ 5.6. The cultures were grown overnight in a shaking water bath for $18 \mathrm{~h}$ at $30^{\circ} \mathrm{C}$. The yeast cells were then collected, washed with phosphate-buffered saline (PBS), counted with a haemocytometer, and adjusted to $10^{7} / \mathrm{ml}$ prior to use.

\section{Antimicrobial peptides}

KSL-W (KKVVFWVKFK-NH2) was synthesized by standard solid-phase procedures [63] with 9-fluorenylmethoxycarbonyl (Fmoc) chemistry in an automatic peptide synthesizer (model 90, Advanced ChemTech, Louisville, KY, USA). The synthetic peptides were then purified by reverse-phase HPLC (series 1100, Hewlett Packard) by means of a Vydac C18 column. Peptide purity was confirmed by MALDI-TOF (matrix-assisted laser desorption/ionization-time of flight) MS (AnaSpec Fremont, CA, USA). The final product was stored in lyophilized format $-20^{\circ} \mathrm{C}$ until use. $\mathrm{KSL}-\mathrm{W}$ solution was prepared, filtered (0.22 um pore size), and used for the experiments. Amphotericin B (Sigma-Aldrich, St. Louis, MO, USA) was dissolved in distilled water to obtain a $250 \mu \mathrm{g} / \mathrm{ml}$ concentration which was also filtered, with the sterile solution stored at $-80^{\circ} \mathrm{C}$ until use.

\section{Effect of KSL-W on C. albicans proliferation}

Proliferation was investigated by placing $10^{4} \mathrm{C}$. albicans in $200 \mu \mathrm{L}$ of Sabouraud dextrose broth in a roundbottom 96-well plate. The C. albicans cultures were supplemented with KSL-W at concentrations of 1, 10, 25, 50, 75, and $100 \mu \mathrm{g} / \mathrm{ml}$. The negative controls were $C$. albicans cultures not supplemented with KSL-W, while the positive controls were $C$. albicans cultures supplemented with amphotericin $B$ at concentrations of 1,5 , and $10 \mu \mathrm{g} / \mathrm{ml}$. The plates were incubated for 5,10 , and

Table 4 Gene expression ( 3 h) under hyphae inducing culture conditions (medium supplemented with $10 \%$ fetal calf serum, with culture incubation at $37^{\circ} \mathrm{C}$ )

\begin{tabular}{|c|c|c|c|c|c|c|c|}
\hline \multirow[t]{2}{*}{ Gene } & \multirow{2}{*}{$\begin{array}{l}\text { Untreated C. albicans } \\
\text { Fold change }^{1}\end{array}$} & \multicolumn{2}{|c|}{ Amphotericin B } & \multicolumn{2}{|c|}{ KSL-W $25 \mu \mathrm{g} / \mathrm{ml}$} & \multicolumn{2}{|c|}{ KSL-W $100 \mu \mathrm{g} / \mathrm{ml}$} \\
\hline & & Fold change $^{1}$ & $p$-value ${ }^{2}$ & Fold change $^{1}$ & p-value ${ }^{2}$ & Fold change $^{1}$ & p-value ${ }^{2}$ \\
\hline$\overline{S A P 2}$ & 0.99 & 3.36 & 0.003 & 0.78 & 0.02 & 0.62 & 0.003 \\
\hline SAP4 & 0.96 & 2.41 & 0.02 & 0.44 & 0.0002 & 0.24 & $<0.0001$ \\
\hline SAP5 & 1.00 & 0.49 & 0.0007 & 0.83 & 0.03 & 0.01 & $<0.0001$ \\
\hline SAP6 & 1.00 & 2.56 & 0.01 & 0.30 & $<0.0001$ & 0.11 & $<0.0001$ \\
\hline EAP1 & 1.00 & 6.06 & $<0.001$ & 1.06 & 0.4 & 0.99 & 0.8 \\
\hline EFG1 & 1.00 & 1.09 & 0.6 & 0.55 & 0.0004 & 0.66 & 0.02 \\
\hline$N R G 1$ & 1.00 & 2.45 & 0.01 & 0.66 & 0.0006 & 0.64 & 0.0005 \\
\hline HWP1 & 1.00 & 0.0055 & $<0.001$ & 0.078 & $<0.0001$ & 0.0035 & $<0.0001$ \\
\hline
\end{tabular}

${ }^{1}$ Fold change was calculated by PCR product of the gene of interest/the PCR product of ACT1 (the house keeping gene), and normalized to the negative control of untreated C. albicans where the expression was considered equal to 1 .

${ }^{2} \mathrm{P}$-values were obtained after comparison of test to negative control (untreated C. albicans). 
Table 5 Gene expression $(6 \mathrm{~h})$ under hyphae inducing culture conditions (medium supplemented with $10 \%$ fetal calf serum, with culture incubation at $37^{\circ} \mathrm{C}$ )

\begin{tabular}{|c|c|c|c|c|c|c|c|}
\hline \multirow[t]{2}{*}{ Gene } & \multirow{2}{*}{$\begin{array}{l}\text { Untreated C. albicans } \\
\text { Fold change }^{1}\end{array}$} & \multicolumn{2}{|c|}{ Amphotericin B } & \multicolumn{2}{|c|}{ KSL-W $25 \mu \mathrm{g} / \mathrm{ml}$} & \multicolumn{2}{|c|}{ KSL-W $100 \mu \mathrm{g} / \mathrm{ml}$} \\
\hline & & Fold change $^{1}$ & p-value ${ }^{2}$ & Fold change $^{1}$ & p-value ${ }^{2}$ & Fold change $^{1}$ & p-value ${ }^{2}$ \\
\hline$\overline{S A P 2}$ & 0.99 & 8.17 & 0.009 & 0.7 & 0.2 & 1.31 & 0.02 \\
\hline SAP4 & 0.96 & 2.58 & 0.03 & 0.73 & 0.04 & 0.72 & 0.04 \\
\hline SAP5 & 1.00 & 0.72 & 0.007 & 0.83 & 0.0004 & 0.56 & 0.006 \\
\hline SAPG & 1.00 & 4.01 & 0.02 & 0.58 & 0.01 & 0.68 & 0.04 \\
\hline EAP1 & 1.00 & 6.36 & 0.001 & 0.44 & 0.008 & 0.73 & 0.003 \\
\hline EFG1 & 1.00 & 1.78 & 0.048 & 0.31 & $<0.0001$ & 0.47 & 0.01 \\
\hline NRG1 & 1.00 & 3.97 & 0.0005 & 0.37 & 0.001 & 0.37 & 0.05 \\
\hline HWP1 & 1.00 & 0.008 & $<0.001$ & 0.09 & 0.001 & 0.03 & $<0.0001$ \\
\hline
\end{tabular}

${ }^{1}$ Fold change was calculated by PCR product of the gene of interest/the PCR product of ACT1 (the house keeping gene), and normalized to the negative control of untreated $C$. albicans where the expression was considered equal to 1 .

${ }^{2} \mathrm{P}$-values were obtained after comparison of test to negative control (untreated C. albicans).

$15 \mathrm{~h}$ prior to cell growth analyses. C. albicans growth was assessed using the (3-(4,5-dimethylthiazol-2-yl)-2, 5-diphenyl tetrazolium bromide) MTT assay (SigmaAldrich) which measures cell growth as a function of mitochondrial activity [64]. Briefly, an MTT stock solution $(5 \mathrm{mg} / \mathrm{ml}$ ) was prepared in PBS and added to each culture at a final concentration of $10 \%(\mathrm{v} / \mathrm{v})$. The C. albicans cultures were then incubated with the MTT solution at $30^{\circ} \mathrm{C}$ for $4 \mathrm{~h}$, after which time the plate was centrifuged for $10 \mathrm{~min}$ at $1200 \mathrm{rpm}$ and the supernatant was removed. The remaining pellet from each well was then washed with warm PBS, with $200 \mu \mathrm{l}$ of $0.04 \mathrm{~N}$ $\mathrm{HCl}$ in isopropanol added to each well, followed by another incubation for $15 \mathrm{~min}$. Absorbance (optical density, OD) was subsequently measured at $550 \mathrm{~nm}$ by means of an xMark microplate spectrophotometer (Bio-Rad, Mississauga, $\mathrm{ON}$, Canada). Results are reported as means \pm SD of three separate experiments.

\section{Effect of KSL-W on C. albicans transition from blastospore to hyphal form}

To determine the effect of KSL-W on the yeast-tohyphae transition, C. albicans $\left(10^{5}\right.$ cells) was first grown in $500 \mathrm{ml}$ of Sabouraud dextrose broth supplemented with $0.1 \%$ glucose and $10 \%$ fetal bovine serum (FBS). KSL-W was then added (or not) to the culture at various concentrations $(1,5,10,15$, and $25 \mu \mathrm{g} / \mathrm{ml})$. The negative controls were the $C$. albicans cultures without antimicrobial peptide, while the positive controls represented the $C$. albicans cultures supplemented with amphotericin B $(1,5$, and $10 \mu \mathrm{g} / \mathrm{ml})$. The hyphaeinducing conditions were previously reported [65], consisting of culture medium supplementation with $10 \%$ fetal calf serum and subsequent incubation at $37^{\circ} \mathrm{C}$. These conditions were used in our experiments. Following incubation for 4 or $8 \mathrm{~h}$, the cultures were observed microscopically and photographed to record C. albicans morphology $(\mathrm{n}=5)$ and the density of $C$. albicans transition was measured.

Effect of KSL-W on C. albicans gene activation/repression C. albicans was subcultured overnight in Sabouraud liquid medium supplemented with $0.1 \%$ glucose, $\mathrm{pH} 5.6$, in a shaking water bath for $18 \mathrm{~h}$ at $30^{\circ} \mathrm{C}$. The yeast cells were then collected, washed with PBS, and counted with a hemocytometer, after which time they were cocultured with or without the antimicrobial peptide under hyphae- or non-hyphae-inducing conditions, as follows.

\section{Effect of KSL-W on gene activation when C. albicans was cultured under non-hyphae-inducing conditions}

C. albicans was co-cultured with either KSL-W $(1,25$, $100 \mu \mathrm{g} / \mathrm{ml})$ or amphotericin B $(1 \mu \mathrm{g} / \mathrm{ml})$ or with none of these molecules (controls) in Sabouraud liquid medium supplemented with $0.1 \%$ glucose, $\mathrm{pH}$ 5.6. The cultures were maintained at $30^{\circ} \mathrm{C}$ for 3 and $6 \mathrm{~h}$.

\section{Effect of KSL-W on gene activation when C. albicans were cultured under hyphae-inducing conditions}

C. albicans was co-cultured with either KSL-W $(1,25$, $100 \mu \mathrm{g} / \mathrm{ml})$ or amphotericin B $(1 \mu \mathrm{g} / \mathrm{ml})$ or with none of these molecules (controls) in Sabouraud liquid medium supplemented with $0.1 \%$ glucose, $\mathrm{pH}$ 5.6. As previously reported, to promote the transition of $C$. albicans from blastospore to hyphal form, the culture medium was supplemented with $10 \%$ fetal calf serum and the incubation was performed for 3 and $6 \mathrm{~h}$ at $37^{\circ} \mathrm{C}$. Following each culture period under both conditions [68], the cultures were centrifuged $10 \mathrm{~min}$ at 13,000 rpm, the supernatants were discarded, and each pellet was suspended thereafter in $0.6 \mathrm{ml}$ of lysis buffer (Glycerol $1 \mathrm{M}$, EDTA $0.1 \mathrm{M})$. Glass beads $(0.425-0.6 \mathrm{~mm}$ in diameter; $0.2 \mathrm{ml})$ were added to each suspended pellet prior to sonication ( $4 \times 1 \mathrm{~min}$, followed by $2 \mathrm{~min}$ of incubation in ice) with 
a MiniBead-beater (Biospec Products, Bartlesville, OK, USA). Following cell lysis, the total RNA was extracted from each sample by means of the Illustra RNAspin Mini kit (GE Health Care UK Limited, Buckingham, UK). Concentration, purity, and quality of the isolated RNA were determined using the Experion system and RNA StdSens analysis kit according to the instructions provided by the manufacturer (Bio-Rad, Hercules, CA, USA).

\section{Quantitative real-time RT-PCR}

The RNA (500 ng of each sample) was reverse transcribed into cDNA by means of the iScript cDNA Synthesis kit (Bio-Rad, Mississauga, ON, Canada). The conditions for the preparation of the cDNA templates for PCR analysis were $5 \mathrm{~min}$ at $25^{\circ} \mathrm{C}, 1 \mathrm{~h}$ at $42^{\circ} \mathrm{C}$, and 5 min at $85^{\circ} \mathrm{C}$. Quantitative PCR (qPCR) was carried out as previously described [36]. The quantity of mRNA transcripts was measured with the Bio-Rad CFX96 realtime PCR detection system. Reactions were performed using a PCR supermix, also from Bio-Rad (iQ SYBR Green supermix). Primers (Table 6) were added to the reaction mix to a final concentration of $250 \mathrm{nM}$. Five microliters of each cDNA sample were added to a $20 \mu \mathrm{l}$ PCR mixture containing $12.5 \mu \mathrm{l}$ of the iQ SYBR Green supermix, $0.5 \mu \mathrm{l}$ of specific primers ACT1, SAP2, SAP4, SAP5, SAP6, HWP1, and EAP1 (Midland Certified Reagent Company, Inc., Midland, TX, USA), as well as

Table 6 Primer sequences used for the qRT-PCR

\begin{tabular}{|c|c|c|}
\hline Gene & Primer sequence $5^{\prime}$ to $3^{\prime}$ & Amp size (bp) \\
\hline \multirow[t]{2}{*}{ ACT1 } & Forward: GCTGGTAGAGACTTGACCAACCA & 87 \\
\hline & Reverse : GACAATTTCTCTTTCAGCACTAGTAGTGA & \\
\hline \multirow[t]{2}{*}{ SAP2 } & Forward: TCCTGATGTTAATGTTGATTGTCAAG & 82 \\
\hline & Reverse : TGGATCATATGTCCCCTITTGTT & \\
\hline \multirow[t]{2}{*}{ SAP4 } & Forward: AGATATTGAGCCCACAGAAATTCC & 82 \\
\hline & Reverse : CAATTTAACTGCAACAGGTCCTCTT & \\
\hline \multirow[t]{2}{*}{ SAP5 } & Forward : CAGAATTTCCCGTCGATGAGA & 78 \\
\hline & Reverse : CATTGTGCAAAGTAACTGCAACAG & \\
\hline \multirow[t]{2}{*}{ SAP6 } & Forward: TTACGCAAAAGGTAACTTGTATCAAGA & 102 \\
\hline & Reverse : CCTTTATGAGCACTAGTAGACCAAACG & \\
\hline \multirow[t]{2}{*}{ ALS3 } & Forward: AATGGTCCTTATGAATCACCATCTACTA & 51 \\
\hline & Reverse : GAGTTITCATCCATACTTGATTTCACAT & \\
\hline \multirow[t]{2}{*}{ HWP1 } & Forward : GCTCAACTTATTGCTATCGCTTATTACA & 67 \\
\hline & Reverse : GACCGTCTACCTGTGGGACAGT & \\
\hline \multirow[t]{2}{*}{ EAP1 } & Forward: CTGCTCACTCAACTTCAATTGTCG & 51 \\
\hline & Reverse : GAACACATCCACCTTCGGGA & \\
\hline \multirow[t]{2}{*}{ EFG1 } & Forward: TATGCCCCAGCAAACAACTG & 202 \\
\hline & Reverse : TTGTTGTCCTGCTGTCTGTC & \\
\hline \multirow[t]{2}{*}{ NRG1 } & Forward: CACCTCACTTGCAACCCC & 198 \\
\hline & Reverse : GCCCTGGAGATGGTCTGA & \\
\hline
\end{tabular}

EFG1 and NRG1 (Invitrogen Life Technologies Inc., Burlington, ON, Canada), and $7 \mu \mathrm{l}$ of RNase/DNase-free water (MP Biomedicals, Solon, OH, USA). Each reaction was performed in a Bio-Rad MyCycler Thermal Cycler. For the qPCR, the CT was automatically determined using the accompanying Bio-Rad CFX Manager. The thermocycling conditions for the ACT1, SAPs 2-4-5-6, and EAP1 were established as $5 \mathrm{~min}$ at $95^{\circ} \mathrm{C}$, followed by 30 cycles of $15 \mathrm{~s}$ at $95^{\circ} \mathrm{C}, 30 \mathrm{~s}$ at $60^{\circ} \mathrm{C}$, and $30 \mathrm{~s}$ at $72^{\circ} \mathrm{C}$, with each reaction performed in triplicate. For the EFG1 and NRG1, the thermocycling conditions were set for $3 \mathrm{~min}$ at $95^{\circ} \mathrm{C}$, followed by 45 cycles of $10 \mathrm{~s}$ at $95^{\circ} \mathrm{C}$, $40 \mathrm{~s}$ at $54^{\circ} \mathrm{C}$, and $40 \mathrm{~s}$ at $72^{\circ} \mathrm{C}$, with each reaction also performed in triplicate. For the HWP1, the conditions were $3 \mathrm{~min}$ at $95^{\circ} \mathrm{C}$, followed by 45 cycles of $10 \mathrm{~s}$ at $95^{\circ} \mathrm{C}, 30 \mathrm{~s}$ at $54^{\circ} \mathrm{C}$, and $40 \mathrm{~s}$ at $72^{\circ} \mathrm{C}$, with each reaction performed in triplicate. The specificity of each primer pair was determined by the presence of a single melting temperature peak. The ACT1 produced uniform expression levels varying by less than 0.5 CTs between sample conditions and thus became the reference gene for this study. The results were analyzed by means of the $2^{-\Delta \Delta \mathrm{Ct}}$ (Livak) relative expression method.

\section{Effect of KSL-W on C. albicans biofilm formation}

C. albicans biofilms were obtained by culturing the yeast on a porous collagen scaffold which facilitated $C$. albicans penetration through the pores and its adhesion to the scaffold through collagen affinity. This also promoted biofilm formation and handling with no cell loss, thus contributing to maintaining the biofilm structure. For this purpose, $5 \mathrm{~mm} \times 5 \mathrm{~mm}$ samples of porous scaffold (Collatape, Zimmer Dental Inc., Carlsbad, CA, USA) were placed into a 24-well plate. The scaffolds were then rinsed twice with culture medium, seeded with $C$. albicans $\left(10^{5}\right.$ cells), and incubated for $30 \mathrm{~min}$ at $30^{\circ} \mathrm{C}$ without shaking to allow for adherence. Fresh Sabouraud medium was added to each well in the presence or absence of various concentrations of KSL-W (1, 10, $25,50,75$, and $100 \mu \mathrm{g} / \mathrm{ml}$ ). Two controls were included in this study: the negative control was $C$. albicans seeded without KSL-W, while the positive control was $C$. albicans seeded with amphotericin B $(1,5$, and $10 \mu \mathrm{g} / \mathrm{ml})$. The $C$. albicans-seeded scaffolds were then incubated for 2, 4, and 6 days at $30^{\circ} \mathrm{C}$. The medium, KSL-W, and amphotericin B were refreshed every $48 \mathrm{~h}$. Following each culture period, C. albicans growth and biofilm formation was assessed by scanning electron microscopy and XTT-menadione assay.

\section{Scanning electron microscopy (SEM) analysis}

Biofilms were fixed in ethylene glycol for $60 \mathrm{~min}$ and rinsed once with sterile PBS. Dehydration was performed in a series of 5-min treatments with ethanol 
solutions of increasing concentration (50, 70, 90, and twice at 100\%). The dehydrated biofilms were kept overnight in a vacuum oven at $25^{\circ} \mathrm{C}$, after which time they were sputter-coated with gold, examined, and imaged ( $\mathrm{n}=4$ ) under a JEOL 6360 LV SEM (Soquelec, Montréal, QC, Canada) operating at a $30 \mathrm{kV}$ accelerating voltage.

\section{$X T T$ reduction assay}

To support the hypothesis that KSL-W quantitatively affects $C$. albicans biofilms, an XTT reduction assay was performed on the KSL-W-treated and control biofilms at defined time points. XTT assay is one of the most useful and accurate methods to investigate microbial biofilm formation. The metabolic activity of the biofilm cells was measured as a reflection of viable cell count. To do so, C. albicans biofilms formed in the porous scaffold with or without KSL-W treatments for 2, 4, and 6 days were subjected to an XTT assay. Fifty microliters of XTT salt solution (1 $\mathrm{mg} / \mathrm{ml}$ in PBS; Sigma-Aldrich) and $4 \mu \mathrm{l}$ of menadione solution $(1 \mathrm{mM}$ in acetone; Sigma-Aldrich) were added to wells containing $4 \mathrm{ml}$ of sterile PBS. The biofilms were then added to the mixture and the plates were incubated at $37^{\circ} \mathrm{C}$ for $5 \mathrm{~h}$, after which time the supernatant was collected to measure the XTT formazan at $492 \mathrm{~nm}$ by means of an xMark microplate spectrophotometer (Bio-Rad, Mississauga, ON, Canada).

\section{Effect of KSL-W on the disruption of mature C. albicans biofilms}

Mature C. albicans biofilms were obtained by culturing C. albicans $\left(10^{5}\right)$ on a porous $3 \mathrm{D}$ collagen scaffold for 6 days at $30^{\circ} \mathrm{C}$ in Sabouraud liquid medium supplemented with $0.1 \%$ glucose at $\mathrm{pH}$ 5.6. The culture medium was refreshed every 2 days. At the end of the 6day culture period, the biofilms were treated (or not) with KSL-W (75 and $100 \mu \mathrm{g} / \mathrm{ml}$ ). Amphotericin Btreated biofilms $(1,5$, and $10 \mu \mathrm{g} / \mathrm{ml})$ were used as the positive controls. The biofilms were continuously incubated (or not) with either KSL-W or amphotericin B for 2, 4, and 6 days, with medium changing every day. KSL-W and amphotericin B were also refreshed at each medium changing. Following each incubation period, SEM and XTT analyses were performed, as described above.

\section{Statistical analysis}

Each experiment was performed at least four times, with experimental values expressed as means \pm SD. The statistical significance of the differences between the control (absence of KSL-W) and test (presence of KSL-W or amphotericin B) values was determined by means of a one-way ANOVA. Posteriori comparisons were performed using Tukey's method. Normality and variance assumptions were verified using the Shapiro-Wilk test and the Brown and Forsythe test, respectively. All of the assumptions were fulfilled. $\mathrm{P}$ values were declared significant at $\leq 0.05$. The data were analyzed using the SAS version 8.2 statistical package (SAS Institute Inc., Cary, NC, USA).

\section{Authors' contributions}

$M R, K P L$, and $A S$ designed the experiments, supervised the research and wrote the paper. ST, AA, and AS performed the experiments and data analyses and contributed to the writing of the paper. Each author read and approved the final manuscript.

\section{Acknowledgements}

This study was supported financially by the United States Army Medical Research and Materiel Command (Award number ERMS No. 12304006) and by a grant from the Fonds Émile-Beaulieu, a Université Laval foundation. The authors also thank Ms. Claire Kingston (Traduction CFK) for proofreading and editing this manuscript.

\section{DOD Disclaimer}

One of the authors (KPL) is a United States Government employee. The work presented is part of his official duties. The opinions or assertions contained herein are the personal views of these authors and are not to be construed as official or reflecting the views of the United States Army or Department of Defense.

\section{Author details}

'Oral Ecology Research Group, Faculty of Dentistry, Laval University, 2420, rue de la Terrasse, Quebec G1V 0A6, QC, Canada. ${ }^{2}$ Department of Biochemistry, Genome Research Chair, College of Science King Saud University, Riyadh, Kingdom of Saudi Arabia. ${ }^{3}$ Dental and Trauma Research Detachment, US Army Institute of Surgical Research, JBSA Fort Sam Houston, San Antonio, TX, USA.

Received: 5 July 2013 Accepted: 4 November 2013 Published: 7 November 2013

\section{References}

1. Arendorf TM, Walker DM: The prevalence and intra-oral distribution of Candida albicans in man. Arch Oral Biol 1980, 25:1-10.

2. Cannon RD, Chaffin WL: Oral colonization by Candida albicans. Crit Rev Oral Biol Med 1999, 10:359-383.

3. Sudbery P, Gow N, Berman J: The distinct morphogenic states of Candida albicans. Trends Microbiol 2004, 12:317-324.

4. Nobile CJ, Nett JE, Andes DR, Mitchell AP: Function of Candida albicans adhesin Hwp1 in biofilm formation. Eukaryot Cell 2006, 5:1604-1610.

5. Li F, Palecek SP: EAP1, a Candida albicans gene involved in binding human epithelial cells. Eukaryot Cell 2003, 2:1266-1273.

6. Sohn K, Urban C, Brunner H, Rupp S: EFG1 is a major regulator of cell wall dynamics in Candida albicans as revealed by DNA microarrays. Mol Microbiol 2003, 47:89-102.

7. Stoldt VR, Sonneborn A, Leuker CE, Ernst JF: Efg1p, an essential regulator of morphogenesis of the human pathogen Candida albicans, is a member of a conserved class of bHLH proteins regulating morphogenetic processes in fungi. EMBO J 1997, 16:1982-1991.

8. Lo HJ, Köhler JR, DiDomenico B, Loebenberg D, Cacciapuoti A, Fink GR: Nonfilamentous C. albicans mutants are avirulent. Cell 1997, 90:939-949.

9. Schaller M, Borelli $C$, Korting HC, Hube B: Hydrolytic enzymes as virulence factors of Candida albicans. Mycoses 2005, 48:365-377.

10. Décanis N, Tazi N, Correia A, Vilanova M, Rouabhia M: Farnesol, a fungal quorum-sensing molecule triggers Candida albicans morphological changes by down-regulating the expression of different secreted aspartyl proteinase genes. Open Microbiol J 2011, 5:119-126.

11. Naglik JR, Challacombe SJ, Hube B: Candida albicans secreted aspartyl proteinases in virulence and pathogenesis. Microbiol Mol Biol Rev 2003, 67:400-428.

12. Hube B, Naglik J: Candida albicans proteinases: resolving the mystery of a gene family. Microbiology 2001, 147:1997-2005. 
13. White TC, Miyasaki SH, Agabian N: Three distinct secreted aspartyl proteinases in Candida albicans. J Bacteriol 1993, 175:6126-6133.

14. White TC, Agabian N: Candida albicans secreted aspartyl proteinases: isoenzyme pattern is determined by cell type, and levels are determined by environmental factors. J Bacteriol 1995, 177:5215-5221.

15. Albrecht A, Felk A, Pichova I, Naglik JR, Schaller M, de Groot P, Maccallum D, Odds FC, Schäfer W, Klis F, Monod M, Hube B:

Glycosylphosphatidylinositol-anchored proteases of Candida albicans target proteins necessary for both cellular processes and host-pathogen interactions. J Biol Chem 2006, 281(2):688-694.

16. van der Weerden NL, Bleackley MR, Anderson MA: Properties and mechanisms of action of naturally occurring antifungal peptides. Cell Mol Life Sci 2013, 70(19):3545-3570.

17. Fjell CD, Hiss JA, Hancock RE, Schneider G: Designing antimicrobial peptides: form follows function. Nat Rev Drug Discov 2012, 11:37-51.

18. Seo MD, Won HS, Kim JH, Mishig-Ochir T, Lee BJ: Antimicrobial peptides for therapeutic applications: a review. Molecules 2012, 17:12276-12286.

19. Campbell EL, Serhan CN, Colgan SP: Antimicrobial aspects of inflammatory resolution in the mucosa: a role for proresolving mediators. J Immunol 2011, 187:3475-3481.

20. Lehrer Rl, Lu W: alpha-Defensins in human innate immunity. Immunol Rev 2012, 245:84-112.

21. Mehra T, Koberle M, Braunsdorf C, Mailander-Sanchez D, Borelli C, et al: Alternative approaches to antifungal therapies. Exp Dermatol 2012, 21:778-782.

22. Zhu S: Discovery of six families of fungal defensin-like peptides provides insights into origin and evolution of the CSalphabeta defensins. Mol Immunol 2008, 45:828-838.

23. Batoni G, Maisetta G, Brancatisano FL, Esin S, Campa M: Use of antimicrobial peptides against microbial biofilms: advantages and limits. Curr Med Chem 2011, 18:256-279.

24. Dziarski R, Gupta D: Review: Mammalian peptidoglycan recognition proteins (PGRPs) in innate immunity. Innate Immun 2010, 16:168-174.

25. Taraszkiewicz A, Fila G, Grinholc M, Nakonieczna J: Innovative strategies to overcome biofilm resistance. Biomed Res Int 2013, 2013:150653. doi: 10.1155/2013/150653.

26. Cota-Arriola O, Cortez-Rocha MO, Burgos-Hernandez A, Ezquerra-Brauer JM, Plascencia-Jatomea M: Controlled release matrices and micro/nanoparticles of chitosan with antimicrobial potential: development of new strategies for microbial control in agriculture. J Sci Food Agric 2013, 93:1525-1536.

27. Dhople V, Krukemeyer A, Ramamoorthy A: The human beta-defensin-3, an antibacterial peptide with multiple biological functions. Biochim Biophys Acta 2006, 1758:1499-1512

28. Joly S, Maze C, McCray PB Jr, Guthmiller JM: Human beta-defensins 2 and 3 demonstrate strain-selective activity against oral microorganisms. J Clin Microbiol 2004, 42:1024-1029.

29. Mooney C, Haslam NJ, Pollastri G, Shields DC: Towards the improved discovery and design of functional peptides: common features of diverse classes permit generalized prediction of bioactivity. PLOS One 2012, 7:e45012.

30. Na DH, Faraj J, Capan Y, Leung KP, DeLuca PP: Stability of antimicrobial decapeptide (KSL) and its analogues for delivery in the oral cavity. Pharm Res 2007, 24:1544-1550.

31. Hong SY, Park TG, Lee KH: The effect of charge increase on the specificity and activity of a short antimicrobial peptide. Peptides 2001, 22:1669-1674.

32. Oh JE, Hong SY, Lee KH: Structure-activity relationship study: short antimicrobial peptides. J Pept Res 1999, 53:41-46.

33. Concannon SP, Crowe TD, Abercrombie JJ, Molina CM, Hou P, et al: Susceptibility of oral bacteria to an antimicrobial decapeptide. J Med Microbiol 2003, 52:1083-1093.

34. Leung KP, Crowe TD, Abercrombie JJ, Molina CM, Bradshaw CJ, et al: Control of oral biofilm formation by an antimicrobial decapeptide. J Dent Res 2005, 84:1172-1177.

35. Baker PJ, Coburn RA, Genco RJ, Evans RT: The in vitro inhibition of microbial growth and plaque formation by surfactant drugs. J Periodontal Res 1978, 13:474-485.

36. Semlali A, Leung KP, Curt S, Rouabhia M: Antimicrobial decapeptide KSL-W attenuates Candida albicans virulence by modulating its effects on Tolllike receptor, human $\beta$-defensin, and cytokine expression by engineered human oral mucosa. Peptides 2011, 32(5):859-867.

37. Okkers DJ, Dicks LM, Silvester M, Joubert JJ, Odendaal HJ: Characterization of pentocin TV35b, a bacteriocin-like peptide isolated from Lactobacillus pentosus with a fungistatic effect on Candida albicans. J App/ Microbio/ 1999, 87:726-734.

38. Dixon DR, Jeffrey NR, Dubey VS, Leung KP: Antimicrobial peptide inhibition of Porphyromonas gingivalis 381-induced hemagglutination is improved with a synthetic decapeptide. Peptides 2009, 30:2161-2167.

39. Raines SM, Rane HS, Bernardo SM, Binder JL, Lee SA, et al: Deletion of Vacuolar Proton-translocating ATPase Voa Isoforms Clarifies the Role of Vacuolar pH as a Determinant of Virulence-associated Traits in Candida albicans. J Biol Chem 2013, 288:6190-6201.

40. Ariyachet C, Solis NV, Liu Y, Prasadarao NV, Filler SG, et al: SR-Like RNA-Binding Protein SIr1 Affects Candida albicans Filamentation and Virulence. Infect Immun 2013, 81:1267-1276.

41. Décanis N, Savignac K, Rouabhia M: Farnesol promotes epithelial cell defense against Candida albicans through Toll-like receptor 2 expression, interleukin- 6 and human beta-defensin 2 production. Cytokine 2009, 45:132-140.

42. Zhang J, Silao FG, Bigol UG, Bungay AA, Nicolas MG, et al: Calcineurin is required for pseudohyphal growth, virulence, and drug resistance in Candida lusitaniae. PLoS One 2012, 7:e44192.

43. Koshlukova SE, Araujo MWB, Baev D, Edgerton M: Released ATP is an extracellular cytotoxic mediator in salivary histatin 5-induced killing ofCandida albicans. Infect Immun 2000, 68:6848-6856.

44. Vylkova S, Jang WS, Li W, Nayyar N, Edgerton M: Histatin 5 initiates osmotic stress response in Candida albicans via activation of the Hog1 mitogenactivated protein kinase pathway. Eukaryot Cell 2007, 6:1876-1888.

45. Jang WS, Bajwa JS, Sun JN, Edgerton M: Salivary histatin 5 internalization by translocation, but not endocytosis, is required for fungicidal activity in Candida albicans. Mol Microbiol 2010, 77:354-370.

46. Ramage G, Vandewalle K, Wickes BL, Lopez-Ribot JL: Characteristics of biofilm formation by Candida albicans. Rev Iberoam Micol 2001, 18:163-170.

47. Banerjee M, Uppuluri P, Zhao XR, Carlisle PL, Vipulanandan G, et al: Expression of UME6, a key regulator of Candida albicans hyphal development, enhances biofilm formation via Hgc1- and Sun41dependent mechanisms. Eukaryot Cell 2013, 12:224-232.

48. da Silva BR, de Freitas VA, Carneiro VA, Arruda FV, Lorenzon EN, et al: Antimicrobial activity of the synthetic peptide Lys-a1 against oral streptococci. Peptides 2013, 42C:78-83.

49. Beckloff N, Laube D, Castro T, Furgang D, Park S, et al: Activity of an antimicrobial peptide mimetic against planktonic and biofilm cultures of oral pathogens. Antimicrob Agents Chemother 2007, 51:4125-4132.

50. Patrzykat A, Friedrich CL, Zhang L, Mendoza V, Hancock RE: Sublethal concentrations of pleurocidin-derived antimicrobial peptides inhibit macromolecular synthesis in Escherichia coli. Antimicrob Agents Chemother 2002, 46:605-614

51. Mason AJ, Chotimah IN, Bertani P, Bechinger B: A spectroscopic study of the membrane interaction of the antimicrobial peptide Pleurocidin. Mol Membr Biol 2006, 23:185-194.

52. Bauerova V, Pichova I, Hruskova-Heidingsfeldova O: Nitrogen source and growth stage of Candida albicans influence expression level of vacuola aspartic protease Apr1p and carboxypeptidase Cpy1p. Can J Microbiol 2012, 58:678-681.

53. Cleary IA, Lazzell AL, Monteagudo C, Thomas DP, Saville SP: BRG1 and NRG1 form a novel feedback circuit regulating Candida albicans hypha formation and virulence. Mol Microbiol 2012, 85:557-573.

54. Nobile CJ, Fox EP, Nett JE, Sorrells TR, Mitrovich QM, et al: A recently evolved transcriptional network controls biofilm development in Candida albicans. Cell 2012, 148:126-138.

55. Murad AM, Leng P, Straffon M, Wishart J, Macaskill S, et al: NRG1 represses yeast-hypha morphogenesis and hypha-specific gene expression in Candida albicans. EMBO J 2001, 20:4742-4752.

56. Braun BR, Kadosh D, Johnson AD: NRG1, a repressor of filamentous growth in C.albicans, is down-regulated during filament induction. EMBO J 2001, 20:4753-4761.

57. Li F, Svarovsky MJ, Karlsson AJ, Wagner JP, Marchillo K, et al: Eap1p, an adhesin that mediates Candida albicans biofilm formation in vitro and in vivo. Eukaryot Cell 2007, 6:931-939.

58. Sharkey LL, MCNemar MD, Saporito-Irwin SM, Sypherd PS, Fonzi WA: HWP1 functions in the morphological development of Candida albicans downstream of EFG1, TUP1, and RBF1. J Bacteriol 1999, 181:5273-5279.

59. Staniszewska M, Bondaryk M, Siennicka K, Kurek A, Orlowski J, et al: In vitro study of secreted aspartyl proteinases Sap1 to Sap3 and Sap4 to Sap6 
expression in Candida albicans pleomorphic forms. Pol J Microbiol 2012, 61:247-256.

60. Lian CH, Liu WD: Differential expression of Candida albicans secreted aspartyl proteinase in human vulvovaginal candidiasis. Mycoses 2007, 50:383-390

61. Hube B, Monod M, Schofield DA, Brown AJ, Gow NA: Expression of seven members of the gene family encoding secretory aspartyl proteinases in Candida albicans. Mol Microbiol 1994, 14:87-99.

62. Puri S, Kumar R, Chadha S, Tati S, Conti HR, et al: Secreted aspartic protease cleavage of Candida albicans Msb2 activates Cek1 MAPK signaling affecting biofilm formation and oropharyngeal candidiasis. PLoS One 2012, 7:e46020.

63. Hong SY, Oh JE, Kwon M, Choi MJ, Lee JH, et al: Identification and characterization of novel antimicrobial decapeptides generated by combinatorial chemistry. Antimicrob Agents Chemother 1998, 42:2534-2541.

64. Denizot F, Lang R: Rapid colorimetric assay for cell growth and survival. Modifications to the tetrazolium dye procedure giving improved sensitivity and reliability. I Immunol Methods 1986, 89:271-277.

65. Li L, Zhang C, Konopka JB: A Candida albicans temperature-sensitive cdc12-6 mutant identifies roles for septins in selection of sites of germ tube formation and hyphal morphogenesis. Eukaryot Cell 2012, 11:1210-1218.

doi:10.1186/1471-2180-13-246

Cite this article as: Theberge et al.: C. albicans growth, transition, biofilm formation, and gene expression modulation by antimicrobial decapeptide KSL-W. BMC Microbiology 2013 13:246.

\section{Submit your next manuscript to BioMed Central and take full advantage of:}

- Convenient online submission

- Thorough peer review

- No space constraints or color figure charges

- Immediate publication on acceptance

- Inclusion in PubMed, CAS, Scopus and Google Scholar

- Research which is freely available for redistribution 